\title{
IMPACT OF METHADONE MAINTENANCE THERAPY ON HIV INCIDENCE IN PERAK, 2008 - 2017: A COX REGRESSION ANALYSIS
}

\author{
Hairul Izwan Abdul Rahman ${ }^{1}$, Nor Aida Sanusi ${ }^{2}$, Muhammad Syafik Ikhwan Salleh ${ }^{3}, \mathrm{Ng}_{\text {Yoon }}$ Yeen ${ }^{4}$, \\ Ismail Ali Mohd Jobran ${ }^{5}$, Nor Suhailah Mohd Hasan ${ }^{6}$ and Siti Nur Umi Aminah Zainal Bahri ${ }^{7}$

\begin{abstract}
${ }^{1}$ Surveillance Complex, Kinta District Health Office, c/o Jelapang Health Clinic, Jalan Jelapang, 30020 Ipoh, Perak, Malaysia

2Pharmaceutical Services Division, Perak State Health Department, c/o Hospital Bahagia Ulu Kinta, 31250 Tanjung Rambutan, Perak, Malaysia

${ }^{3}$ Pharmacy Unit, Taiping Hospital, Jalan Taming Sari, 34000 Taiping, Perak, Malaysia

${ }^{4}$ Medical Division, Perak State Health Department, Jalan Panglima Bukit Gantang Wahab, 30000 Ipoh, Perak, Malaysia

${ }^{5}$ Pharmacy Unit, Batang Padang District Health Office, Jalan Temoh, 35000 Tapah, Perak, Malaysia

${ }^{6}$ Pharmacy Unit, Kuala Kangsar District Health Office, Jalan Sultan Idris Shah 1, 33000 Kuala Kangsar, Perak, Malaysia ${ }^{7}$ Pharmacy Unit, Perak Tengah District Health Office, Jalan Ipoh-Lumut, Bandar Seri Iskandar, 32610 Seri Iskandar, Perak, Malaysia
\end{abstract}

Corresponding Author: Hairul Izwan Abdul Rahman

E-mail: drhairul@moh.gov.my

\section{ABSTRACT}

In 2005, Ministry of Health introduced the Needle Syringe Exchange Program (NSEP) and Methadone Maintenance Therapy (MMT) program as a part of Harm Reduction program to combat HIV infection in Malaysia among people who inject drug (PWIDs). Expenditures were estimated approximately RM10 millions per year to establish and sustain the NSEP and MMT centres. This study examined the impact of MMT program on preventing HIV seroconversion among registered MMT clients that are people who inject drug (PWIDs), and to identify other predictors of HIV seroconversion among this group. This was a retrospective cohort study done in the state of Perak involving a total of 212 randomly selected MMT clients registered between 2008-2017 in 6 clinics. This study looks at data collected from the last ten-year cohort from baseline to follow-up. A questionnaire was used to obtain socio-demographic data, sexual and drugs abuse history. Test results for HIV were obtained from medical records. Cox regression analysis was performed to examine factors associated with seroconversion and Kaplan-Meier analysis to estimate HIV survival time. This study displayed that both Methadone take home supply (HR 10.4, 95\% Cl: $1.6-68.8)$ and unprotected sexual practice (HR 5.9, 95\%Cl: 1.1 - 31.5) shown higher risks of HIV seroconversion compared to DOTS and condom practice among MMT clients respectively. Mean survival for HIV seroconversion among MMT clients was 104.44 (95\% Cl: 101.85 - 107.04) months. This study provides reliable evidence that MMT program markedly reduces incidence of HIV infection among people who inject drug (PWIDs).

Key words: Methadone, Cox regression, HIV seroconversion, survival analysis

\section{INTRODUCTION}

Opioid addiction among human beings have been a long existing epidemic across regions worldwide and Malaysia is no exception. The Malaysian Psychiatric Association predicted that about one million people are addicted to heroin or other illegal substances in Malaysia ${ }^{1}$. Generally, opiate addicts will start using heroin via inhalation route and later, via intravenous route due to increasing tolerance effect and thus needle-sharing and unsafe injection practices were preeminently very common.

HIV transmission have been primarily linked, not only to intravenous drug users (IVDUs), but also through unprotected vaginal or anal intercourse whether homosexual, bisexual or heterosexual, as well as through oral sex with another HIV-infected person. Between 1986 and 2006 in Malaysia, nearly $73 \%$ of reported HIV were primarily people who inject drug (PWID)2. In 2005, the Ministry of Health has initiated Methadone Maintenance Therapy (MMT) as part of the Harm Reduction Program to prevent HIV due to the large number of HIV cases attributed to PWID behaviour ${ }^{2}$. Since approved for use in the United States in 1947, Methadone substitution has been used in most Western countries as the standard treatment for opiate addiction and were consistently shown over time that it is the most effective treatment intervention. The main objectives of the MMT program are to modify PWID behaviours and to reduce transmission of blood-borne diseases such as HIV, Hepatitis B and Hepatitis C among PWIDs. Intriguingly, the 2013 Malaysian AIDS Council Annual Report has provided a comprehensive picture of the opposite trend, i.e. $73 \%$ of new HIV cases were transmitted through unprotected sexual activities rather than PWIDs which comprises of only $22 \%^{3}$. 
In 1983, illicit drug abuses were declared as a national security threat and Malaysia's number one enemy. In 2003, The Dangerous Drugs Act had been revised, adding section 15 DDA, allowing dangerous drug offenders to be imprisoned not exceeding 2 years ${ }^{4}$.

In the inauguration year, 18 selected health facilities in this country pioneered the MMT to a total of 1,240 clients $^{5}$. Since then, many more MMT centres, including public and private hospitals and clinics as well as prisons and National Anti-Drug Agency centres, established to increase PWIDs accessibility to MMT. Furthermore, two other components of Harm Reduction Program that has been introduced to PWIDs were Needle Syringe Exchange Program (NSEP) and distribution of free condoms to control both needle-sharing and unprotected sexual practices. Based on the 2013 Malaysian AIDS Council Annual Report, the decreasing trend of new HIV cases among PWIDs could be attributed to the three harm reduction intervention programs, i.e. MMT, NSEP and protective sexual practice.

Perak specific research on the effectiveness of methadone substitution is almost entirely absent. Therefore, this study was conducted to determine the impact of MMT program among registered PWIDs in the state of Perak and to find out if NSEP and protective sexual practice are independent predictors of HIV seroconversion inhibition among registered PWIDs.

\section{METHODS}

\section{Study Design}

This study was designed to evaluate the effects of maintenance methadone treatment (MMT) on formerly opioid addicts in the prevention of HIV. This is a retrospective cohort study conducted on MMT clients in 6 health centres in Perak i.e. Raja Permaisuri Bainun Ipoh Hospital, Taiping Hospital, Teluk Intan Hospital, Jelapang Health Clinic, Taiping Health Clinic and Langkap Health Clinic. It is imperative to mention these MMT centres were deliberately selected as convenient sample.

This study looks at data collected from the last 10year cohort from baseline to follow-up. Enrollment was restricted to eligible persons who were at least 18 years of age, Malaysian citizen and were registered for MMT program specifically from 1st January 2008 until 31st December 2017. Exclusion criteria were registered MMT clients who whether relocated to other facilities, lost to follow-up (dropout, deceased, imprisoned), had been discharged less than 1 year, and/or with concurrent psychiatric illnesses. A total of 212 participants were selected by using systematic random sampling method.

\section{Ethical Consideration}

Ethical approval from National Medical Research Registry (NMRR) committee was received prior to the study stipulated on full data confidentiality (ID: NMRR-16-474-29613). Participants' informed consent was obtained individually before enrollment to this study. Participants were assured all information was used for research only and strictly confidential.

\section{Sampling Calculation}

Metzger et al. (1993) stated that the median survival time of control subjects was 1.5 years $^{6}$. Accordingly, an accrual interval of 1.5 years was allocated for sample calculation in this study. The sample size was calculated using Power and Sample Size Calculation version 3.1.2. by Dupont \& Plummer $(2014)^{7}$.

Assuming if the true hazard ratio of control subjects is 6.28 in relative to experimental subjects, the researchers need a minimum sample size of 109 respondents to be able to reject the null hypothesis with $80 \%$ confidence. To compensate for about $50 \%$ of defaulter rate based on Perak's statistical data, and about $20 \%$ of expected rejection rate, the researchers configured a minimum sample size of 186 subjects was prerequisite for this study. The Type I error probability associated with this test of null hypothesis is 0.05 .

\section{Data Analysis}

Statistical analyses were performed using SPSS Version 15.0. Seroconversion time was the interval calculated from the date of first seronegative test to the date of first seropositive test. Cox regression analysis was performed to determine predictors of HIV seroconversion. In the model, potential predictors were ethnic group, marital status, educational level, person they stay with, enrolment age, distance to methadone clinic, Methadone take home supply and condom practice. Parameters with missing values were omitted from the analysis. The significant level was preset at $p$-value $<0.05$. Kaplan-Meier analysis was performed to determine mean survival time of HIV seroconversion.

\section{Data Collection}

This study was conducted in January 2018. This study mostly relied on data of 212 participants drawn from the 10 years ongoing cohort from the 2008 as baseline year to the end of 2017 of all MMT clients in the state of Perak and further improvements of data were done through face-toface interview with participants using a structured questionnaire form.

The study protocol was divided into 4 sections: Section A consists of participants' demographic data such as age, gender, ethnicity, marriage status, education level, occupation, monthly income, primary reason for unemployment, living style, household inhabitants, and distance between home to methadone centre. Section B 
consists of participant's medical history such as HIV, HBV and HCV status at baseline and followup. Section $C$ consists of treatment information such as source of referral, history of confinement to prison or National Anti-Drug Agency detention centres (NADA, PUSPEN), current methadone dosage, types of methadone treatment either maintenance or reduction and either patient is on regular direct observed therapy (DOTS) or has the privilege to regular take away supply. Lastly, section D consists of information about other HIV high risk behaviours such as unprotected sexual activities and needle-sharing.

\section{RESULTS}

Of the follow-up sample $(n=212)$, all respondents were on maintenance methadone therapy (MMT), accordingly, none were on reduction methadone treatment. All respondents were male, comprised of Malays (71.7\%), Chinese (17.0\%) and Indian (10.4\%). Married clients (47.2\%) was comparable to those single $(44.8 \%)$, and the remaining were divorcees. Two-third of respondents had highest education at secondary school (76.4\%) and onefifth at primary school (20.3\%). Five respondents were degrees or diplomas holders $(2.4 \%)$ and only two did not have any formal education. One-third of respondents had history of been arrested once or more in their lifetimes (38.2\%). No homeless respondent found. All respondents lived either in their personal, parents or rented houses. However, this study was not able to clearly define respondents living style and household inhabitants. The average distance between their dwellings and methadone clinics was $5.8 \mathrm{~km}$ $( \pm 3.3)$. Remarkably, considerable number of respondents worked (89.2\%), whom mostly were engaged in daily paid odd jobs and to lesser extent, secured monthly salary occupations. Monthly mean income based on working respondents' average wages was RM1,493 $( \pm 818)$. Three of unemployed respondents were not in good health, and the remaining who were rather in good physical shape either shy, cautious or hesitant to cite their reasons for unemployment. (Table 1)

Table 1: Socio-demographic variables of respondents $(n=212)$

\begin{tabular}{|c|c|c|c|}
\hline Variable & $\mathrm{n}$ & $\%$ & Mean (SD) \\
\hline \multicolumn{4}{|l|}{ Gender } \\
\hline Male & 212 & 100 & \\
\hline Female & 0 & 0 & \\
\hline \multicolumn{4}{|l|}{ Ethnic groups } \\
\hline Malay & 152 & 71.7 & \\
\hline Chinese & 36 & 17.0 & \\
\hline Indian & 22 & 10.4 & \\
\hline Others & 2 & 0.9 & \\
\hline \multicolumn{4}{|l|}{ Marital status } \\
\hline Single & 95 & 44.8 & \\
\hline Married & 100 & 47.2 & \\
\hline Divorced & 17 & 8.0 & \\
\hline \multicolumn{4}{|l|}{ Educational level } \\
\hline No formal education & 2 & 0.9 & \\
\hline Primary education & 43 & 20.3 & \\
\hline Secondary education & 162 & 76.4 & \\
\hline Diploma / Degree & 5 & 2.4 & \\
\hline \multicolumn{4}{|l|}{ Age } \\
\hline Started addiction & & & $22.61(7.19)$ \\
\hline Methadone enrolment & & & $37.53(10.60)$ \\
\hline Study & & & $43.17(11.21)$ \\
\hline \multicolumn{4}{|l|}{ Employment status } \\
\hline Employed & 189 & 89.2 & \\
\hline Unemployed & 23 & 10.8 & \\
\hline Monthly income (RM) & & & $1493.06(817.87)$ \\
\hline \multicolumn{4}{|c|}{ Imprisonment / Locked-up } \\
\hline Yes & 81 & 38.2 & \\
\hline No & 131 & 61.8 & \\
\hline
\end{tabular}


At the time of follow-up, almost all respondents were active MMT clients (97.2\%), and only 6 dropouts, i.e. 4 absconded and 2 voluntarily resigned. Most of them signed up voluntarily into the MMT program (74.5\%) and the remaining via referral from National Anti-Drug Agency (9.0\%) and NGOs $(2.8 \%)$ or introduced by friends $(11.3 \%)$ and family members (2.4\%). Mean age of respondents at the time of follow-up was 43.2 years $( \pm 11.2)$ and average duration of respondents in MMT program was 56.7 months $( \pm 24.9)$. Mean age of respondents at first opioid addiction was 22.6 years $( \pm 7.2)$ and mean age at MMT enrolment was 37.5 years $( \pm 10.6)$. Mean dosage of methadone was $59.4 \mathrm{mg}( \pm 38.0$, range: 5 - $160 \mathrm{mg})$ daily and nearly all respondents were engaged in Directly Observed Therapy Strategy (93.9\%). (Table 2)

Table 2: Methadone program characteristics among respondents

\begin{tabular}{lccc}
\hline Variable & $\mathrm{n}$ & $\%$ & Mean (SD) \\
\hline Source of referral & 19 & 9.0 & \\
NADA & 158 & 74.5 & \\
Walk-in & 6 & 2.8 & \\
NGO & 24 & 11.3 & \\
Friends & 5 & 2.4 & \\
Others & & & \\
Latest treatment status & 206 & 97.2 & \\
$\quad$ Active & 4 & 1.9 & $56.73(24.86)$ \\
$\quad$ Default & 2 & 0.9 & $5.84(3.28)$ \\
Voluntarily Discharge & & & \\
Duration (months) in the program & & & \\
Distance to clinic (KM) & & & \\
DOTS & 199 & 93.9 & \\
Yes & 13 & 6.1 & \\
No & & & \\
Latest Dosage (mg) & & & \\
\hline
\end{tabular}

At the time of follow-up, only 4 respondents confessed continuing injecting heroin while on MMT $(1.9 \%)$, as well two of them had needles sharing. More than half respondents responded they were engaged in unsafe sexual activities (homosexual, bisexual or heterosexual) at least once in the previous year (53.3\%). Only one-third of respondents who said that they had been involved in unsafe sexual activities used condoms during intercourse (35.4\%). The prevalence of HIV among respondents was $2.4 \%(n=5)$ at baseline and at follow-up, raised to $3.3 \%(n=7)$. Hepatitis $C$ had been highly prevalent among respondents, was reported 50 -folds higher $(57.1 \%)$ at baseline as compared to HIV and at follow-up, increased to $59.4 \%$. Hepatitis B prevalence was lower among respondents as compared to HIV at baseline and remaining unchanged at follow-up (1.4\% vs $1.4 \%)$, perhaps due to Hepatitis B vaccination. Regrettably, HIV seroconversion among dropout respondents was not investigated. Thus, HIV seroconversion rates between active respondents and dropouts could not be compared. (Table 3 ).
Cox regression analysis of the respondents shown that HIV seroconversion in MMT program has higher associations with both Methadone take home supply (HR 10.4, 95\% Cl: 1.6 - 68.8) and unprotected sexual practice (HR 5.9, 95\%Cl: 1.1 31.5) compared to DOTS and condom practice among MMT clients respectively. No differences were found with regards to marital status, ethnicity, employment, person they stay with, age of enrolment to MMT program, MMT dosage and distance from MMT centres to dwellings on the outcome of HIV among MMT clients (Table 4).

Result from Kaplan-Meier analysis demonstrated that mean survival time for HIV seroconversion of MMT client was 104.44 months $(95 \% \mathrm{Cl}$ : $101.85-$ 107.04) (Figure 1). Further log-rank test pointed out DOTS has a more desirable longer HIV survival time (mean 105.2 months $( \pm 1.2)$ than take-home dose (mean 70.3 months $( \pm 7.6)(p=0.014)$ (Figure 2). 
Table 3: Risk practices \& HIV, HBV and HCV serological status

\begin{tabular}{|c|c|c|}
\hline Variable & $\mathrm{n}$ & $\%$ \\
\hline \multicolumn{3}{|l|}{ Currently still injecting drugs } \\
\hline Yes & 4 & 1.9 \\
\hline No & 208 & 98.1 \\
\hline \multicolumn{3}{|l|}{ Sharing needles $(n=4)$} \\
\hline Yes & 2 & 50.0 \\
\hline No & 2 & 50.0 \\
\hline \multicolumn{3}{|l|}{ Sexually active } \\
\hline Yes & 113 & 53.3 \\
\hline No & 99 & 46.7 \\
\hline \multicolumn{3}{|c|}{$\begin{array}{l}\text { Condom use among sexually active respondents }(n= \\
\text { 113) }\end{array}$} \\
\hline Yes & 40 & 35.4 \\
\hline No & 73 & 64.6 \\
\hline $\begin{array}{l}\text { Condom use frequency } \\
\text { (from } 10 \text { sex acts) }\end{array}$ & \multicolumn{2}{|c|}{$\begin{array}{l}\text { Mean } 5.12(3.17) \\
\quad \text { Median } 4.00\end{array}$} \\
\hline Prevalence (\%) & Enrolment & Latest \\
\hline HIV status & 2.4 & 3.3 \\
\hline Hep B status & 1.4 & 1.4 \\
\hline Hep C status & 57.1 & 59.4 \\
\hline
\end{tabular}

Table 4: Significant and important factors associated with HIV seroconversion: A Cox regression analysis

\begin{tabular}{|c|c|c|c|}
\hline Variable & $\mathrm{n}(\%)$ & $\mathrm{HR}$ & $95 \% \mathrm{Cl}$ \\
\hline $\begin{array}{l}\text { Ethnic group } \\
\text { Non-Malay } \\
\text { Malay }\end{array}$ & $\begin{array}{c}56(11.1) \\
148(88.9)\end{array}$ & 0.54 & $0.07-4.23$ \\
\hline $\begin{array}{l}\text { Registration Age } \\
<40 \text { years old } \\
\geq 40 \text { years old } \\
\text { Mean registration age }\end{array}$ & $\begin{array}{c}123(60.3) \\
81(39.7) \\
36.84\end{array}$ & $\begin{array}{c}0.85 \\
\text { Referent } \\
0.95\end{array}$ & $\begin{array}{l}0.12-6.04 \\
0.85-1.07\end{array}$ \\
\hline $\begin{array}{l}\text { DOTS } \\
\text { Yes } \\
\text { No }\end{array}$ & $\begin{array}{c}191(93.6) \\
13(6.4)\end{array}$ & $\begin{array}{c}\text { Referent } \\
10.44^{*}\end{array}$ & $1.59-68.77$ \\
\hline Mean Methadone dosage (mg) & 58.80 & 1.01 & $0.99-1.03$ \\
\hline $\begin{array}{l}\text { Condom use } \\
\text { Yes } \\
\text { No }\end{array}$ & $\begin{array}{c}40(19.6) \\
164(80.4)\end{array}$ & $\begin{array}{c}\text { Referent } \\
5.92^{*}\end{array}$ & $1.11-31.47$ \\
\hline $\begin{array}{l}\text { Marital status } \\
\text { Ever married } \\
\text { Single }\end{array}$ & $\begin{array}{c}114(55.9) \\
90(44.1)\end{array}$ & $\begin{array}{c}\text { Referent } \\
3.74\end{array}$ & $0.59-23.76$ \\
\hline $\begin{array}{l}\text { Distance } \\
<5 \mathrm{~km} \\
\geq 5 \mathrm{~km}\end{array}$ & $\begin{array}{c}80(39.2) \\
124(60.8)\end{array}$ & $\begin{array}{c}\text { Referent } \\
0.65\end{array}$ & $0.11-3.66$ \\
\hline $\begin{array}{l}\text { Stay } \\
\text { Family } \\
\text { Others }\end{array}$ & $\begin{array}{c}179(87.7) \\
25(12.3)\end{array}$ & Referent 1.23 & $0.12-12.88$ \\
\hline
\end{tabular}


$\mathrm{HR}=$ Hazard ratio, $\mathrm{Cl}=$ Confidence interval

\section{Survival Function}

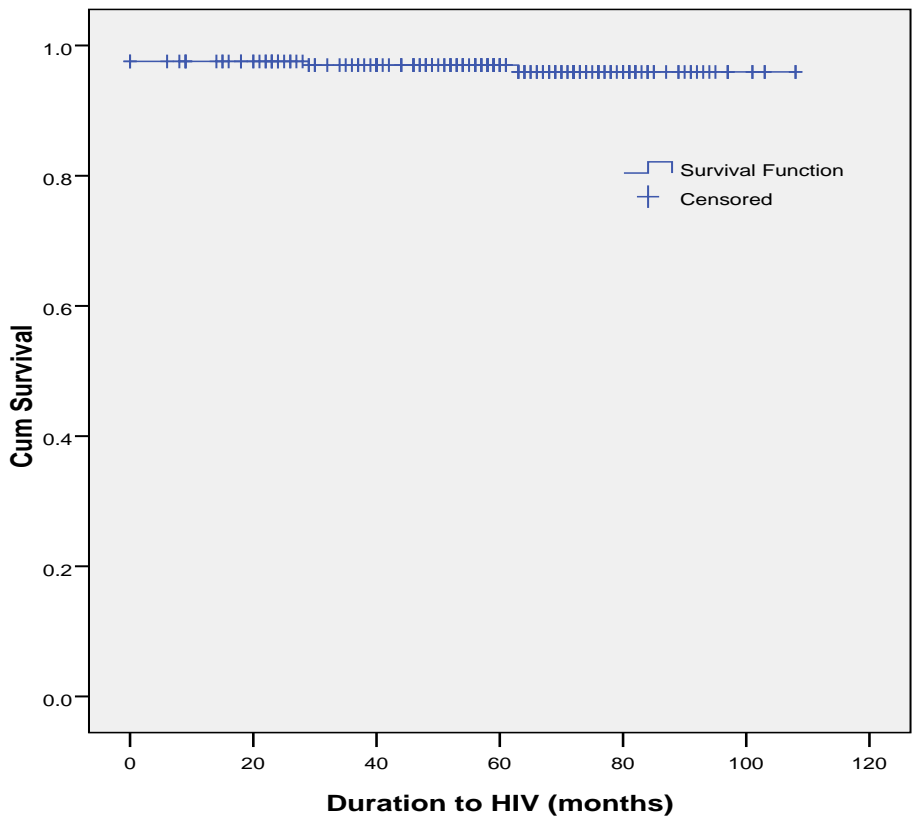

Mean for HIV survival time is 104.44 months $( \pm 1.3,95 \% \mathrm{Cl}$ : $101.8-107.0)$

Figure 1: Cumulative survival of HIV seroconversion among MMT patients

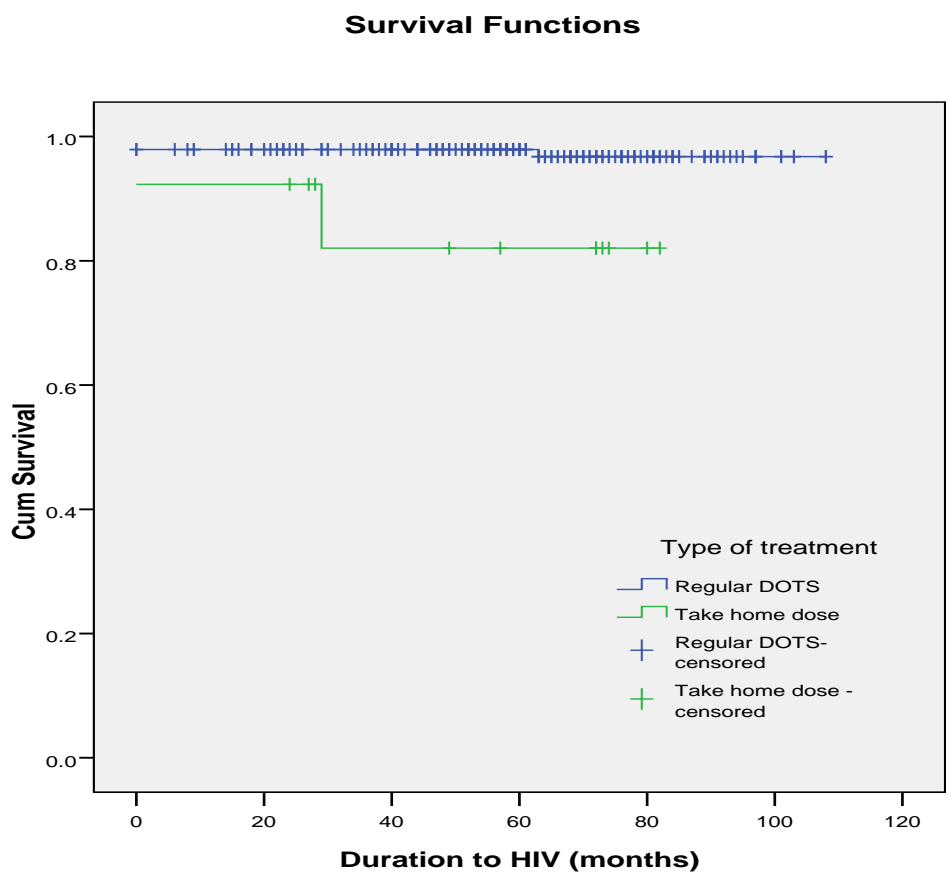

DOTS: Mean 105.24 (1.22) months, Take home dose Mean 70.26 (7.61) months Log rank test, $\mathrm{p}$-value $=0.014$

Figure 2: Plot of Kaplan-Meier estimate of survival probability for HIV stratified by type of treatment

\section{DISCUSSION}

While maintenance methadone treatment (MMT) has been officially initiated by Ministry of Health in Malaysia since 2005, there was little reports on its accomplishment in reducing HIV infection among people who inject drug (PWIDs). Hence, this study was designed to evaluate the effects of
MMT on formerly opioid addicts in preventing HIV infection. This study was conducted to determine seroconversion rate of HIV infection among active MMT clients in Perak.

In this study, comparison of seroconversion rates between active MMT clients and dropouts could not be done. Nevertheless, this study shown 
seroconversion rate for HIV infection among MMT clients in Perak was considerably lower $(0.9 \%)$ than reported seroconversion rates in the untreated PWIDs (0.67\%-0.84\% per injection $\left.{ }^{8,9}\right)$. This finding is consistent with other studies that staying longer in MMT associated with less HIV incidents ${ }^{10,11}$. The finding is aligned with reports from numerous studies that methadone therapy can reduce risk of HIV infection by circumventing the injection related behaviour ${ }^{12}$.

This study also exemplifies other positive impact of maintenance methadone treatment on MMT clients. Firstly, HCV seroconversion rate among MMT clients was significantly lower $(2.3 \%)$ than the untreated PWIDs $(20.7 \%)^{13}$. This finding is compatible to a cohort study over a 7-year followup by Zou et al. in China (2015) which reported moderate to sharp declines in both HIV and HCV seroconversion rates among MMT clients who continue treatment ${ }^{11}$.

Secondly, this study, indeed, shown merely $1.9 \%$ respondents were still injecting heroin while on MMT. As consequence, HIV risks related to injecting drug such as shared needles, did not clean shared needles with bleach, shared cookers and backloading/frontloading could be reduced considerably among MMT clients.

Thirdly, this study shown very high retention rate after 1 year (97.2\%). Many studies had been conducted in other part of the world and reported positive result when patients stayed in MMT program. For instant, Woody et al. (1999) reported that participants who remained in MMT program showed reduction of heroin injected in the last 30 days $^{14}$. Thiede et al. (2000) reported that subjects who constantly active or briefly left but rejoined again MMT program were less likely to backslide to drugs or has lesser HIV risk behaviours compared to those who permanently left MMT program ${ }^{15}$.

Despite of selection by means of random sampling, all respondents were males and mostly within reproductive age, i.e. mean enrollment age to MMT program was 37.5 years $( \pm 10.60)$ and mean age of respondents at the time of follow-up was 43.2 years $( \pm 11.2)$. This finding is consistent with a study by Mohamad et al. (2010) ${ }^{16}$. However, these two socio-demographic parameters might have influence on patient's retention rate in MMT program. A study by Kelly et al. (2011) concluded that female participants had higher retention rate compared to male participants after 3 months follow-up ${ }^{17}$. Since this study did not include female participants, gender difference on patient's retention rate in MMT program could not be evaluated.

This study shown that Methadone take home supply had 10 folds higher risk to contact HIV infection compared to DOTS among MMT clients. According to Varenbut et al. (2007), patients who were given Methadone take home supply were more likely to acquire Methadone diversion later $^{10}$. Hence, this study validated that DOTS surpassed the Methadone take home supply in reducing chance of Methadone diversion among MMT clients. Compellingly, Thiede et al. (2000) contended that despite of methadone diversion, those continued injecting, who continued MMT program injected less frequently, less likely reusing needles and were less often buying drugs, compared to those who resigned MMT program permanently ${ }^{15}$.

However, this finding contradicted a few other reports such as one by Gerra et al. (2011) who proposed that non-supervised Methadone take home supply had a better retention outcome compared to supervised DOTS ${ }^{18}$. Nevertheless, this contradictive finding could be due to association with behavioural incentives and other benefits that needed to be identified.

The prevalence of respondents sexually active in unsafe sexual activities was as high as 53\% and only one-third (35.4\%) of this faction practices condoms during unsafe sexual activities. This observation is to some extent better than the 2012 $\mathrm{MOH}$ report (IBBS) where condoms practice was $26.7 \%$ among sexually active PWID ${ }^{19}$. Regardless of MMT, unprotected sexual practice with another HIV-infected person can cause HIV infection to MMT clients. By chance, according to Lollis et al. (2000), methadone patients had fewer sexual partners and greater use of condoms compared to non-methadone patients ${ }^{20}$.

This study has some limitations. Firstly, this study had a relatively small sample size. Hence, very few active respondents were HIV seroconverted. This might be the explanation for only 2 parameters were found to be associated with HIV seroconversion. Secondly, HIV testing was repeated merely every twelve months during follow-ups. The recommended HIV testing intervals in high risk groups is 3 months. Thus, seroconversion duration relied on the negative or positive results of planned blood tests, rather than the actual recent infections. Thirdly, this study was undoubtedly susceptible to deception of respondents and manipulative behaviours associated with drug addicts causing discomfort, uncertainty and feared being deceived among medical staff. Viz versa respondents themselves were concerned of being stigmatized and mistreated especially concerning Methadone prescription. The degree of manipulation will vary with the questions, for example respondents are less likely to be honest to questions relating to sexual behaviour or drug use, than they are about socio-demography.

\section{CONCLUSIONS}

It is concluded that MMT program has considerably reduces incidence of HIV infection among people who inject drug (PWIDs). Furthermore, protective sexual practice and Needle Syringe Exchange 
Program (NSEP) are two independent predictors to minimise HIV seroconversion. It is imperative to sustain operation of methadone centres to combat HIV attributed to PWIDs. Likewise, the findings also indicate the substantial need to expand MMT program; so that, limited availability to the service must not becoming an excuse deterring the program from benefiting more PWIDs. Integration of MMT and condom practice by PWIDs use in harm reduction program would reduce the dual risk of HIV infection.

\section{ACKNOWLEDGEMENTS}

We would like to convey great appreciation to all staffs whom contributed to this study. Special thanks to Mrs. Noor Azilah Mat Yaacob for proofreading this report. We are also very grateful to Dato' Dr. Hasan Merican, the director of Perak State Health Department, and Dr B. Venugopalan, the deputy director of Perak State Health Department, for guiding and supporting this study.

\section{CONFLICT OF INTERESTS}

The authors have declared that no conflict of interest exists.

\section{REFERENCES}

1. Malaysian Psychiatric Association. Drug Addiction 2006. www.psychiatrymalaysia.org/article. php?aid=90 (accessed 14 February 2016

2. Malaysian AIDS Council. Annual Report 2006. www.mac.org.my/v3/pdf/report2006.pdf (accessed 14 February 2016)

3. Malaysian AIDS Council. Annual Report 2013. www.mac.org.my/v3/wp-

content/uploads/2014/05/Annual-Report-

2013_A4_FA_22052013-web.pdf (accessed 14

February 2016)

4. Gill JS, Rusdi AR, Ong Hui K, and Jawan R. History of Illicit Drug Use In Malaysia-A Review. International Journal of Addiction Sciences 2010; 1(1): 1-6

5. Kaur S, Mohd HB and Mohamed MN. Projek perintis program rawatan terapi gantian (RTG) menggunakan methadone di Pusat Khidmat AADK. Journal Antidadah Malaysia 2009, 5(1): 1-30.

6. Metzger DS, Woody GE, McLellan AT et al. Human immunodeficiency virus seroconversion among intravenous drug users in-and out-of-treatment: an 18-month prospective follow-up. JAIDS Journal of Acquired Immune Deficiency Syndromes 1993; 6(9):1049-1056.
7. Dupont WD and Plummer WD. Power and Sample Size Calculation tool version 3.1.2. http://biostat.mc.vanderbilt.edu/wiki/Main /PowerSampleSize (Downloaded on 1st February 2016)

8. Kaplan EH, Heimer R. A model-based estimate of HIV infectivity via needle sharing. J Acquir Immune Deffici Syndr 1992; 5(11): 1116-1118

9. Hudgens MG, Longini Jr. IM, Halloran ME et al. Estimating the transmission probability of human immunodeficiency virus in injecting drug users in Thailand. Appl Statist 2001; 50(1): $1-14$

10. Varenbut $M$, Teplin $D$, Daiter $J$ et.al. Tampering by office-based methadone maintenance patients with methadone take home privileges: a pilot study. Harm Reduction Journal 2007; 4: 15. www.ncbi.nlm.nih.gov/pmc/articles/PMC213 4923 (accessed 12 December 2017)

11. Zou $X$, Ling $L$ and Zhang $L$. Trends and risk factors for HIV, HCV and syphilis seroconversion among drug users in a methadone maintenance treatment programme in China: a 7-year retrospective cohort study. BMJ open 2015; 5(8). bmjopen.bmj.com/content/5/8/e008162 (accessed 12 December 2017)

12. Bruce RD. Methadone as HIV Prevention: High Volume Methadone sites to decrease HIV Incidence rates in Resource limited Settings. International Journal of Drug Policy 2010; 21(2): 122-124

13. alencia La Rosa J, Ryan P, Alvaro-Meca A et al. HCV Seroconversion in a cohort of people who use drugs followed in a mobile harm reduction unit in Madrid: Breaking barriers for HCV elimination. PLOS ONE 2018: e0204795. (accessed 15 November 2018)

14. Woody GE, Bruce D, Korthuis PT et al. HIV risk reduction with buprenorphine-naloxone or methadone: findings from a randomized trial. Journal of Acquired Immune Deficiency Syndromes 1999; 66(3): 288-293

15. Thiede $\mathrm{H}$, Hagan $\mathrm{H}$ and Murrill CS. Methadone treatment and hiv and hepatitis band $\mathrm{C}$ risk reduction among injectiors in the Seattle area. Journal of Urban Health 2000; 77(3): $331-345$

16. Mohamad N, Abu Bakar NH, Musa $\mathrm{N}$ et al. Better retention of Malaysia opiate dependents treated with high dose methadone in methadone maintenance therapy. Harm Reduction Journal 2010; 7: 30. www.harmreductionjournal.com/content/7/ 1/30 (accessed 12 December 2017) 
17. Kelly SM, O'Grady KE, Mitchell SG et al. Predictors of Methadone treatment retention from a multi-site study: A Survival analysis. Drug and Alcohol Dependence 2011; 117(2-3): 170-175

18. Gerra G, Saenz E, Busse A et al. Supervised daily consumption, contingent take-home incentive and non-contingent take-home in methadone maintenance. Progress in Neuropsychopharmacology \& Biological Psychiatry 2011; 35(2): 483-489

19. $\mathrm{MOH}$ Malaysia. Integrated Biological and Behavioural Surveillance Survey (IBBS) 2012. www.moh.gov.my (accessed 12 July 2017)

20. Lollis CM, Strothers HS, Chitwood DD et al. Sex, Drugs and HIV: Does Methadone Maintenance Reduce Drug Use and Risky Sexual Behavior? Journal of Behavioral Medicine 2000; 23(6): 545-557 